\title{
Uncovering Meaningful Correlation between Student Academic Performance and Library Material Usage
}

\section{Shun Han Rebekah Wong and T.D. Webb}

\begin{abstract}
Academic libraries must demonstrate empirically that library usage does contribute positively to student academic performance and, thereby, to the university's effectiveness. While customary academic library assessment practices may not be sufficient for this purpose, the Hong Kong Baptist University (HKBU) Library undertook an experimental project, which intended to establish a mathematical correlation between student library material usage and their cumulative grade point average (GPA). Taking 2007 to 2009 graduates as samples, with 8,701 pairs of data, the HKBU Library was able to demonstrate its impact on student learning outcomes.
\end{abstract}

\section{Objective}

The ways in which universities assess the value and performance of their member libraries have changed dramatically, especially in these difficult budgetary times. Merely reporting collection size, circulation data, usage of reference and instructional services, and other facets may not be sufficient for the university administration. Academic libraries must demonstrate their value and impact on their universities' teaching mission to remain in a competitive and viable position within the institution. Being able to show empirically that library usage does contribute positively to student academic performance became one of our pressing tasks. We started with one variable that we were most confident had a positive impact on student learning: library material usage.

The Hong Kong Baptist University (HKBU) Library initiated a highly experimental project, making use of 2007 to 2009 graduates as the sample, to investigate if a mathematical correlation exists between student cumulative grade point average (GPA) and their loans of books and audiovisual materials. A total of 8,701 cases were involved. We understand that book and multimedia checkouts alone cannot present a full picture of library material use, as monographs and media may be important to some disciplines but not others. To provide a more comprehensive view, a brief discussion about the use of electronic resources will be supplemented in the later part of this paper.

Shun Han Rebekah Wong is Assistant Librarian in the Multimedia Services Section and T.D. Webb is previous University Librarian, both at Hong Kong Baptist University Library; e-mail: rebekahw@hkbu. edu.hk, webbt@hawaii.rr.com. Sincere thanks go to Dr. Tong Chong Sze (previous Academic Registrar, $H K B U$ ) and Mr. Manson Yiu (Executive Officer, Academic Registry, HKBU). Without their cooperation, this project could not have been successfully completed and accomplished in a timely fashion. 
This is a unique project because the authors know of no other study that has approached library assessment in this manner and with this scale.

\section{Literature Review}

Libraries have a long history of measuring their performance and impact on users. As early as 1924, the American Library Association prepared a practical guideline and tool for libraries to evaluate their maintenance, administration, and service. ${ }^{1}$ In 1950, the Library Association (UK) thoroughly assessed the United Kingdom's public library service. ${ }^{2}$ Institutions or individuals writing about academic library assessment only became more common later. For example, in 1974, Charles Weinberg developed an interesting and pioneer Bayesian approach to determining the information value of the resources provided by an academic library, through studying user evaluation of individual items. ${ }^{3}$

The breadth of the literature about library assessment, or more specifically academic library assessment, is even more impressive. If we input a search statement with terms like "academic libraries," "assessment," "evaluation," and "user surveys" in any library science database, we can easily pull out thousands of articles that discuss assessment practices and assessment cultures found in the university library sector. However, year by year, academic libraries tended to use the same several assessment tools.

Between 2000 and 2001, the Digital Library Federation (DLF) successfully interviewed 71 library professionals at 24 member institutions about their libraries' assessment practices and concerns. ${ }^{4}$ These institutions were mainly leading academic libraries in the United States and the United Kingdom. Five years later, the Association of Research Libraries (ARL) conducted a similar survey, evaluating the assessment efforts of 24 large academic libraries in the United States. ${ }^{5}$ Both studies came up with a similar result. An analysis and synthesis of these studies turned up the following assessment methods:

- Surveys/Questionnaires/Focus Group Interviews

- Usability Studies/Discount Usability Research Method (a less expensive heuristic approach)

- Usage Studies/Transaction Log Analysis

- Process Analysis/Improvement Studies

- Space/Facility Studies

- Card-Sorting Tests (used to solve or determine vocabulary problems of Web sites)

None of these assessment methods can measure the impact of libraries on student learning outcomes. User surveys and focus group interviews are good tools for understanding user needs, expectations, and satisfaction, but they are anecdotal, qualitative measures, and hence imprecise for scientific measurement. Even the more standardized LibQUAL+, which has gained extensive popularity over recent years, shares the same problem. It can measure student perceptions only that do not necessarily match with real learning outcomes. ${ }^{6}$ Usability studies and cardsorting tests are best suited for assessing Web sites and digital products; usage studies of library resources, reference service, library instruction, and other services can only show usage trends; process analysis and space/facility studies also fail to evaluate a library's contribution toward student learning.

In fact, some university and library administrators did realize the insufficiency of these customary assessment methods. The literature shows increasing attention to library outcome assessment. Patrick Leonard, the Vice Chancellor for Academic Services of the Purdue University North Central (PUNC), clearly stated the need for the PUNC Library to demonstrate "a relationship between the nature of students' library use and their academic performance" before its requested budget could be approved. ${ }^{7}$ For example, he raised, "do those who actively use library collections 
and services perform better than their non-using peers?" Ronald Powell also suggested that "in an era in which academic libraries are more and more in competition for financial support with other important enterprises on their campuses, it is becoming increasingly important for them to be able to justify their costs, if not their existence." ${ }^{8}$ He further stressed that "we need to know how students' use of libraries affect their academic performance." ${ }^{\prime 9}$

Although the literature shows the importance of measuring the relationship between student library usage and their academic performance, only few studies have actually been undertaken. One of the most famous studies was conducted by Knapp in 1966. He found that students who attended more library skills programs acquired higher grades and GRE scores. ${ }^{10}$ Robinson and Schegl (2004) found a statistically significant correlation between citation behavior and assignment grade but suggested that the correlation might have been based more on quantity of citations than on quality. ${ }^{11}$

In accessing the relationship between book loans and academic success, Barkey (1965) found that students who checked out books got higher GPAs than others. ${ }^{12}$ However, due to the technological limitation in those days, Barkey showed in the same paper that this result was "not very reliable." In a more recent study, De Jager (1997) was able to demonstrate a positive relationship between student course grades and their book loans. However, his study involved only 240 students and two courses..$^{13}$ The authors could not find any other published research findings discussing the measurement of the relationship between student academic performance and their book checkouts.

\section{Experimental Design}

An essential prerequisite for this study was the approval and support from the HKBU's administration for the exchange of information between the library that keeps historic circulation data and the Academic Registry (AR) that manages student academic information. The University Librarian conducted meetings with the Academic Vice-President, Academic Registrar, Vice President (Administration), and Director of General Administration for this purpose. After getting the university's support, in November 2009 the authors started to meet with the Academic Registrar and his colleagues to discuss the details of the cooperation. To protect the privacy of the graduates, library colleagues were not allowed to have the GPA data with the student's identification, which included the student number and student name in this case. Eventually, we agreed to adopt these procedures:

1. For each sample group (we will define "sample group" later), the library prepared an Excel table with student numbers, student names, graduation years, the program of study, and checkout data, and sent it to AR;

2. AR prepared a list of student numbers that were missing in the previous files for the library (we found the library's system had some errors in the data of graduation year);

3. The library added the information of the missing graduates in the files and sent them again to AR; and

4. AR replaced student numbers and student names with corresponding GPA data and shuffled the order of rows before sending them to the library.

\section{Samples \& Populations}

The subjects of this study were all HKBU students who had graduated within the last three years (from 2007 to 2009) with cumulative GPA given. A total of 8,701 students were identified. The two selected independent variables in this analysis were:

1. Graduation GPA of the students (denoted as "GPA"), ranging from 1.82 to 4.00 .

2. The number of times these students had checked out books and AV materials during their study at $\mathrm{HKBU}$, not 
taking the number of renewals into account (denoted as "CHKOUT"). This data ranged from 0 to 1,054 .

Cases (pairs of data) were first divided into 53 sample groups, according to their study major (a couple of examples: Translation, Biology) and level of study (undergraduate or graduate level). (Please refer to table 1.) This arrangement was based on the belief that different subject disciplines had different criteria or internal guidelines to assign GPA values, so cases across programs of study were not comparable. Moreover, students' information behaviors are strongly associated with their subject interests and academic level. ${ }^{14}$

\begin{tabular}{|c|c|c|c|c|c|c|c|c|c|}
\hline \multicolumn{10}{|c|}{$\begin{array}{l}\text { TABLE } 1 \\
\text { h Corresponding Sample Sizes }\end{array}$} \\
\hline \multicolumn{2}{|c|}{ Sample Group } & \multicolumn{3}{|c|}{ Sample Size (n) } & \multicolumn{2}{|c|}{ Sample Group } & \multicolumn{3}{|c|}{ Sample Size (n) } \\
\hline Discipline & Level $^{*}$ & $\leq 30$ & $31-200$ & $\geq 201$ & Discipline & Level $^{*}$ & $\leq 30$ & $31-200$ & $\geq 201$ \\
\hline \multicolumn{5}{|c|}{ FACULTY OF ARTS } & \multicolumn{5}{|c|}{ FACULTY OF SCIENCE } \\
\hline \multirow{2}{*}{ Chi Lang \& Lit } & UGS & & $\mathrm{Y}$ & & \multirow{2}{*}{ Biology } & UGS & & $\mathrm{Y}$ & \\
\hline & GS & & $\mathrm{Y}$ & & & GS & & $\mathrm{Y}$ & \\
\hline \multirow{2}{*}{ Eng Lang \& Lit } & UGS & & $\mathrm{Y}$ & & \multirow{2}{*}{ Chemistry } & UGS & & $\mathrm{Y}$ & \\
\hline & GS & Y & & & & GS & & $\mathrm{Y}$ & \\
\hline Humanities & UGS & & $\mathrm{Y}$ & & \multirow{2}{*}{ Computer Sc } & UGS & & & $\mathrm{Y}$ \\
\hline Language Std & GS & & $\mathrm{Y}$ & & & GS & & $\mathrm{Y}$ & \\
\hline \multirow{2}{*}{ Music } & UGS & & $\mathrm{Y}$ & & \multirow{2}{*}{ Mathematics } & UGS & & $\mathrm{Y}$ & \\
\hline & GS & & $\mathrm{Y}$ & & & GS & & $\mathrm{Y}$ & \\
\hline \multirow{2}{*}{ Religion \& Phil } & UGS & & $\mathrm{Y}$ & & Physics & UGS & & $\mathrm{Y}$ & \\
\hline & GS & & $\mathrm{Y}$ & & \multicolumn{5}{|c|}{ FACULTY OF SOCIAL SCIENCES } \\
\hline \multirow{2}{*}{ Translation } & UGS & & $\mathrm{Y}$ & & Education & GS & & & $\mathrm{Y}$ \\
\hline & GS & & $\mathrm{Y}$ & & \multirow{2}{*}{ Geography } & UGS & & $\mathrm{Y}$ & \\
\hline \multicolumn{5}{|c|}{ SCHOOL OF BUSINESS } & & GS & Y & & \\
\hline \multirow{2}{*}{ Accountancy } & UGS & & & $\mathrm{Y}$ & Gov't \& Int'1 Std & UGS & & $\mathrm{Y}$ & \\
\hline & GS & & & $\mathrm{Y}$ & \multirow{2}{*}{ History } & UGS & & $\mathrm{Y}$ & \\
\hline \multirow{2}{*}{ Economics } & UGS & & & $\mathrm{Y}$ & & GS & & $\mathrm{Y}$ & \\
\hline & GS & $\mathrm{Y}$ & & & \multirow{2}{*}{ Physical Ed } & UGS & & $\mathrm{Y}$ & \\
\hline Finance & UGS & & & $\mathrm{Y}$ & & GS & & $\mathrm{Y}$ & \\
\hline \multirow{2}{*}{ Human Res Mgt } & UGS & & $\mathrm{Y}$ & & \multirow{2}{*}{ Sociology } & UGS & & $\mathrm{Y}$ & \\
\hline & GS & & $\mathrm{Y}$ & & & GS & Y & & \\
\hline Marketing & UGS & & $\mathrm{Y}$ & & \multirow{2}{*}{ Social Work } & UGS & & $\mathrm{Y}$ & \\
\hline China Business & UGS & & $\mathrm{Y}$ & & & GS & & $\mathrm{Y}$ & \\
\hline Business Mgt & GS & & $\mathrm{Y}$ & & \multicolumn{5}{|l|}{ OTHER } \\
\hline SCHOOL OF CO & MUNICA & & & & & UGS & & & $\mathrm{Y}$ \\
\hline & UGS & & $\mathrm{Y}$ & & Cningedine & GS & & $\mathrm{Y}$ & \\
\hline & GS & & $\mathrm{Y}$ & & & UGS & & $\mathrm{Y}$ & \\
\hline Communication & UGS & & & $\mathrm{Y}$ & & GS & $\mathrm{Y}$ & & \\
\hline Std & GS & & & $\mathrm{Y}$ & & & & & \\
\hline & UGS & & $\mathrm{Y}$ & & UGS denotes & lderge & & udents & id GS \\
\hline Jominansin & GS & & $\mathrm{Y}$ & & & & & & \\
\hline
\end{tabular}


According to Corder \& Foreman, "the minimum sample size for using a parametric statistical test varies among texts... $[\mathrm{M}]$ ost researchers suggest $n>30 . " 15$ Among the 53 sample groups that we identified, 5 of them had sample size not greater than 30 and thus were invalid. (They are shaded in grey in table 1.) We used the remaining 48 groups as our final samples. The sample size of these 48 groups ranged from 31 to 1,223.

The corresponding population of each sample group is all HKBU current students and graduates who share the same study major and level of study. For example, the sample group <Journalism - UGS $>$ is intended to provide inferences, whenever possible, to all HKBU students/ graduates who take/took journalism as their major in their undergraduate study.

\section{Statistical Methods Used}

For each valid sample group, we used the Pearson's Correlation for the analysis. This method is the most common method used to determine the degree of linear dependence between two variables (which were GPA and CHKOUT in this study). The classic interpretation of the correlation coefficients (r) in behavioral sciences was established by Cohen first in 1983. (Please see table 2 for his approach.) In behavioral sciences, an $\mathrm{r}$ value of 0.8

\begin{tabular}{|c|c|c|}
\hline \multicolumn{3}{|c|}{$\begin{array}{c}\text { TABLE } 2 \\
\text { Interpretation of Correlation } \\
\text { Coefficients in Behavioral Sciences }{ }^{16}\end{array}$} \\
\hline $\begin{array}{c}\text { r for a } \\
\text { Positive } \\
\text { Relationship }\end{array}$ & $\begin{array}{c}\mathrm{r} \text { for a } \\
\text { Negative } \\
\text { Relationship }\end{array}$ & $\begin{array}{l}\text { Relationship } \\
\text { Strength }\end{array}$ \\
\hline 1.0 & -1.0 & Perfect \\
\hline 0.5 & -0.5 & Large \\
\hline 0.3 & -0.3 & Medium \\
\hline 0.1 & -0.1 & Small \\
\hline 0.0 & 0.0 & None \\
\hline
\end{tabular}

is already very high and infrequently occurs. Correlation coefficients (r) are also not based on a linear scale. For example, $\mathrm{r}=0.6$ is not twice as strong as $\mathrm{r}=0.3$.

A two-tailed significance test was then carried out on the sample correlation coefficient (r) to examine if we could provide valid inferences from the sample to the corresponding population. As the common practice, our null hypothesis was that the two variables in question have a zero correlation in the population $\left(\mathrm{H}_{0}: \rho=0\right)$, where $\rho$ represents the correlation coefficient of the population. The alternative hypothesis was that the two variables are related $\left(\mathrm{H}_{\AA}: \rho \neq 0\right)$. We set the significance criterion $(\alpha)$ as 0.05 , which is a widely used standard in behavioral sciences. ${ }^{17}$ By using this value, there was

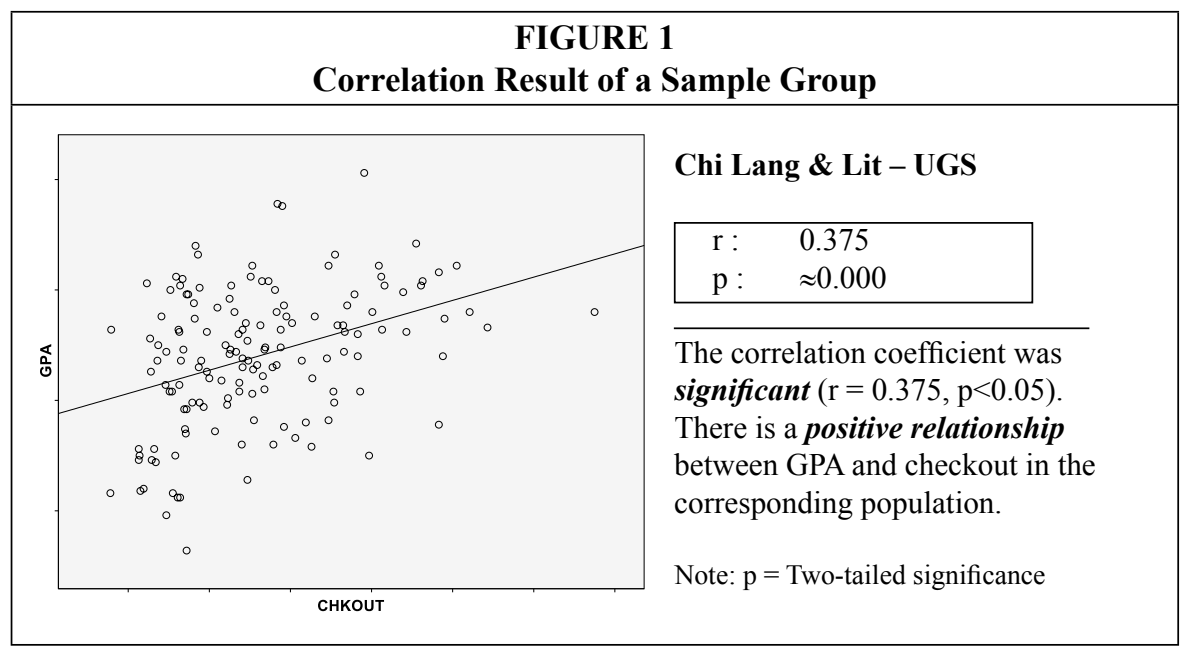


a 95 percent chance that any observed statistical differences were real and not due to chance.

There are a number of factors affecting the result of a significance test, which does not solely depend on the correlation coefficient $(\mathrm{r})$. For example, the $\mathrm{r}$ value of 0.119 in the sample group <Education - GS> was significant, most probably due to its large sample size of 1,223 . In comparison to $<$ Physical Ed - UGS $>$, although its $r=0.154$, it failed to pass the significance test. In other words, the corresponding population of <Physical Ed - UGS> was statistically proven to have no clear relationship between the two testing variables, even though a positive correlation existed in the sample.

To further explain our methodologies, the correlation result of a sample group is presented as an illustrative example. (See figure 1.) Due to privacy reasons, this graph does not have labels (values of scales) displayed. We also transformed the scales, so that all dots appeared in the centre of the graph. This kind of arrangement does not affect the relationship between the variables.

\section{Findings}

Among the 48 valid sample groups, 31 sample groups (65 percent) were statistically proven to have a positive relationship between GPA and CHKOUT in the corresponding population (see figure 2). These sample groups are listed in table 3. No sample groups were found to have a negative correlation between the two variables. The remaining 35 percent had no clear relationship.

The correlation coefficients ( $r$ ) of the above 31 sample groups ranged from 0.119 (<Education - GS) >) to 0.494 $(<$ Mathematics - GS $>$ ). There were a number of sample groups having correlation strength very close to "large." They included: <Humanities - UGS $>$ with $\mathrm{r}=0.472,<$ Translation $-\mathrm{GS}>$ with $\mathrm{r}=0.471$, and $<$ Mathematics - GS $>$ with $\mathrm{r}=0.494$.

Within each Faculty/School, the percentage of sample groups that were

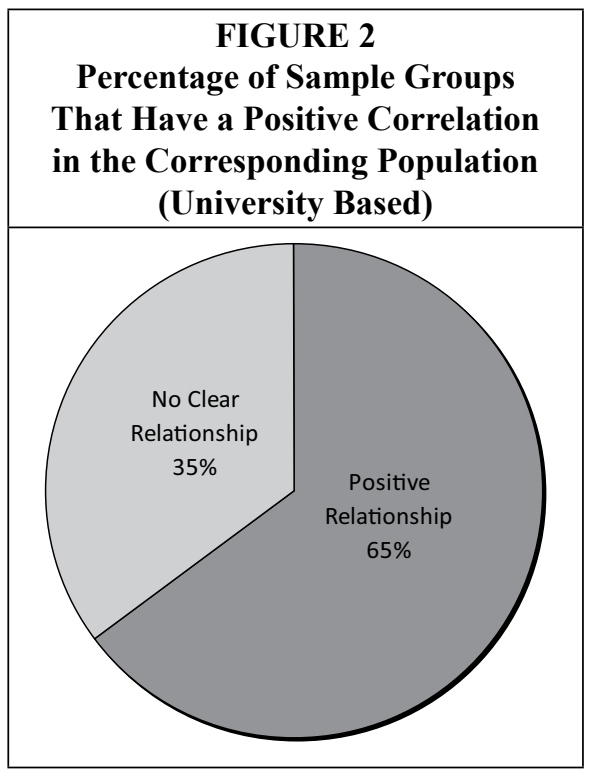

proven to have a positive correlation in the corresponding population is illustrated in figure 3.

\section{Discussion \& Further Investigations}

From the results, we can make two conclusions for the students of Academy of Visual Arts, Faculty of Social Sciences, Faculty of Arts, School of Communication, and Faculty of Science. Either or both of these two conclusions were statistically proven to be valid.

Conclusion One: Most students follow the inference that the more library books and audiovisual materials they use, the higher GPAs they acquire.

Conclusion Two: Most students follow the inference that the higher GPAs they have, the more library books and audiovisual materials they use.

No matter which factor (monograph and multimedia usage or students with higher GPA) is the cause or determinant 


\begin{tabular}{|c|c|c|c|}
\hline \multicolumn{4}{|c|}{$\begin{array}{r}\text { The } 31 \text { Sample Groups Tr } \\
\text { Corresp }\end{array}$} \\
\hline \multicolumn{2}{|c|}{$\begin{array}{l}\text { Sample Groups That Passed the } \\
\text { Significance Test }\end{array}$} & \multirow{2}{*}{$\begin{array}{c}\text { Sample r } \\
0.375\end{array}$} & \multirow{2}{*}{$\begin{array}{l}\text { Affiliated Faculty/School } \\
\text { Faculty of Arts }\end{array}$} \\
\hline Chi Lang \& Lit & UGS & & \\
\hline Chi Lang \& Lit & GS & 0.245 & \\
\hline Eng Lang \& Lit & UGS & 0.236 & \\
\hline Humanities & UGS & 0.472 & \\
\hline Language Std & GS & 0.228 & \\
\hline Music & UGS & 0.270 & \\
\hline Translation & UGS & 0.318 & \\
\hline Translation & GS & 0.471 & \\
\hline Accountancy & UGS & 0.147 & \multirow[t]{4}{*}{ School of Business } \\
\hline Economics & UGS & 0.146 & \\
\hline Human Res Mgt & GS & 0.199 & \\
\hline China Business & UGS & 0.211 & \\
\hline Film & UGS & 0.274 & \multirow[t]{4}{*}{ School of Communication } \\
\hline Communication Std & GS & 0.131 & \\
\hline Journalism & UGS & 0.258 & \\
\hline Journalism & GS & 0.274 & \\
\hline Chi Medicine & UGS & 0.176 & School of Chinese Medicine \\
\hline Biology & GS & 0.195 & \multirow[t]{5}{*}{ Faculty of Science } \\
\hline Chemistry & GS & 0.228 & \\
\hline Mathematics & UGS & 0.163 & \\
\hline Mathematics & GS & 0.494 & \\
\hline Physics & UGS & 0.424 & \\
\hline Education & GS & 0.119 & \multirow[t]{8}{*}{ Faculty of Social Sciences } \\
\hline Geography & UGS & 0.210 & \\
\hline Gov’t \& Int'l Std & UGS & 0.244 & \\
\hline History & UGS & 0.265 & \\
\hline History & GS & 0.357 & \\
\hline Physical Ed & GS & 0.331 & \\
\hline Sociology & UGS & 0.304 & \\
\hline Social Work & UGS & 0.253 & \\
\hline Visual Arts & UGS & 0.207 & Academy of Visual Arts \\
\hline
\end{tabular}




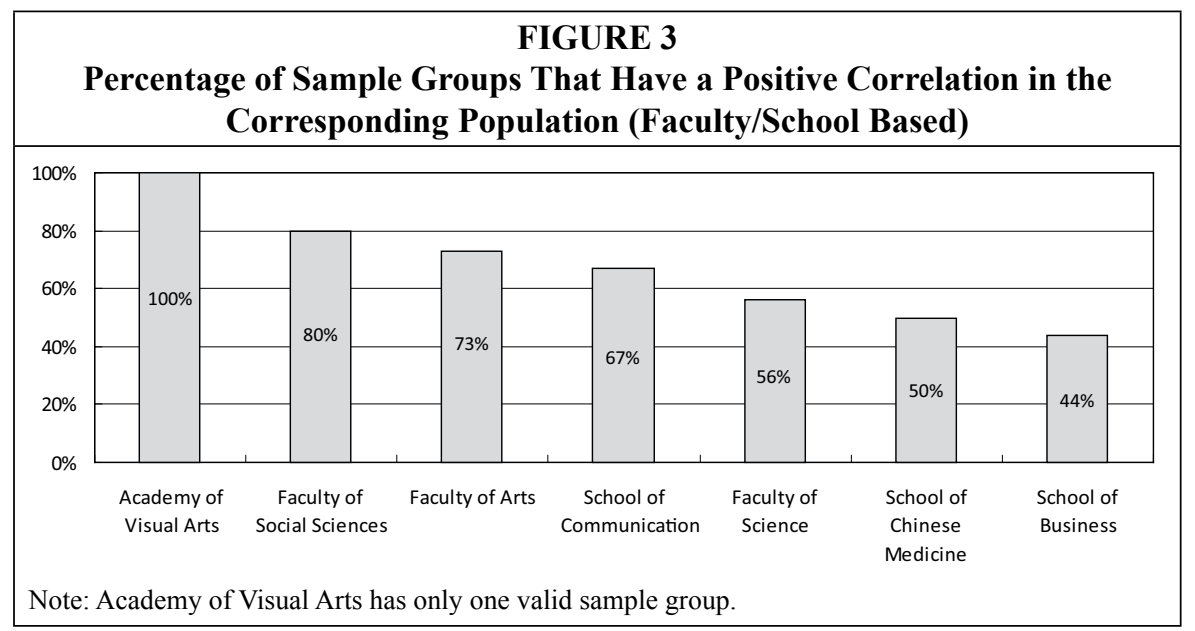

of the relationship, we proved that these two factors are positively correlated for all or most departments of these five Faculties/Schools.

This result brings us (and, one hopes, also other libraries) meaningful implications. First, this study can serve as strong evidence to show the university administration that the library plays an important role in student learning and their academic success for these five Faculties/Schools. Even though some people may choose not to accept Conclusion One, they cannot deny the proven fact that students who have higher GPAs use (or like to use) more monographs and multimedia resources that are provided by the library. The importance of the library is still soundly proven.

We can also make use of this study as a helpful method to justify a strengthened monograph and audiovisual material budget to the university. Even though we are in the Internet era, the results demonstrate that some students (especially those studying Visual Arts, Social Sciences, Arts, and Communication) are still heavily reliant on monographs and audiovisual materials for their study. This confirmed idea can also help collections librarians have a better understanding on how much emphasis to give to monograph and multimedia purchases for different disciplines.
For HKBU, this result had attracted considerable discussions among the university administrators, who then became more interested in the work the library is doing. They decided to give us a small amount of extra funding to investigate if a similar relationship exists between student GPAs and their attendance of library instruction workshops.

\section{Further Investigations}

However, one may quickly come to a conclusion that the library has not made significant (or enough) contribution to student learning for the students of School of Chinese Medicine and School of Business. In response to this possible comment, we thought that a usage study of electronic resources might be useful.

We made use of 2004-2009 usage data of the library's subscribed electronic resources for analysis, covering both online books and online journals. We selected this range of data for analysis, since more than 90 percent of students who graduated between 2007 and 2009 (our subjects) carried out their study within the period from 2004 to 2009. We first classified all electronic resources into Faculty/School -based categories, according to the content of their collections. Then, through assuming the electronic resources used were related to the students' programs of study, we came up with an interesting result. It showed 
the average number of searches made per student per year. (Please refer to figure 4.)

Due to the complication of this task and the fact that this further study was beyond the scope and primary research of this paper, we admit that the exact calculated figures were not very accurate. For example, we could not include any multidisciplinary electronic resources in this analysis, as it was impossible to classify any of them into one single Faculty/ School category. However, the distribution, which is far more important in this case, can serve as a good reference for us.

The scales of the horizontal axes ( $\mathrm{x}$ axes) of figures 3 and 4 are the same; Faculty/School names are listed in the same order for both figures. By comparing these two figures, we can easily notice that they are the opposite of each other. Figure 3 is a downward curve, whereas figure 4 goes upward. In other words, the Faculties/Schools whose student GPAs were less correlated with book and AV material loans, their students used more electronic resources. To better understand the actual impact of library material usage on the students of School of Chinese Medicine and School of Business, we believe another relationship analysis for the use of electronic resources and GPA is needed.

\section{Limitations of the Primary Study}

To yield a correlation result that could provide the best inference to the popula- tion, the ideal sampling method is to select graduates randomly from each year, starting from when the Departments (subject disciplines) were first established till now. However, not all this data, especially the circulation data of earlier years, is stored. It was already our best attempt to take 2007 to 2009 graduates as samples that required us to retrieve circulation transactions starting from 1998. More important, we believe this arrangement cannot have any negative impact on the conclusions we derived from the results.

Another major limitation relates to the statistical method itself. Correlation analysis can only reflect the relationship between two sets of data, including (1) if an association exists, (2) if the association is a positive or a negative relationship, and (3) the strength of the association. Correlation tests cannot tell the cause-and-effect relationship. Therefore, through this study, we cannot simply make a conclusion that the use of books and audiovisual materials is statistically proven to be one of the determinant factors of a higher GPA for the graduate students of Mathematics, undergraduate students of Humanities, and so on. Another possible scenario could be that the students who have higher GPAs tend to use more books and multimedia materials. Yet, as mentioned before, this study and the results are still meaningful in various aspects.

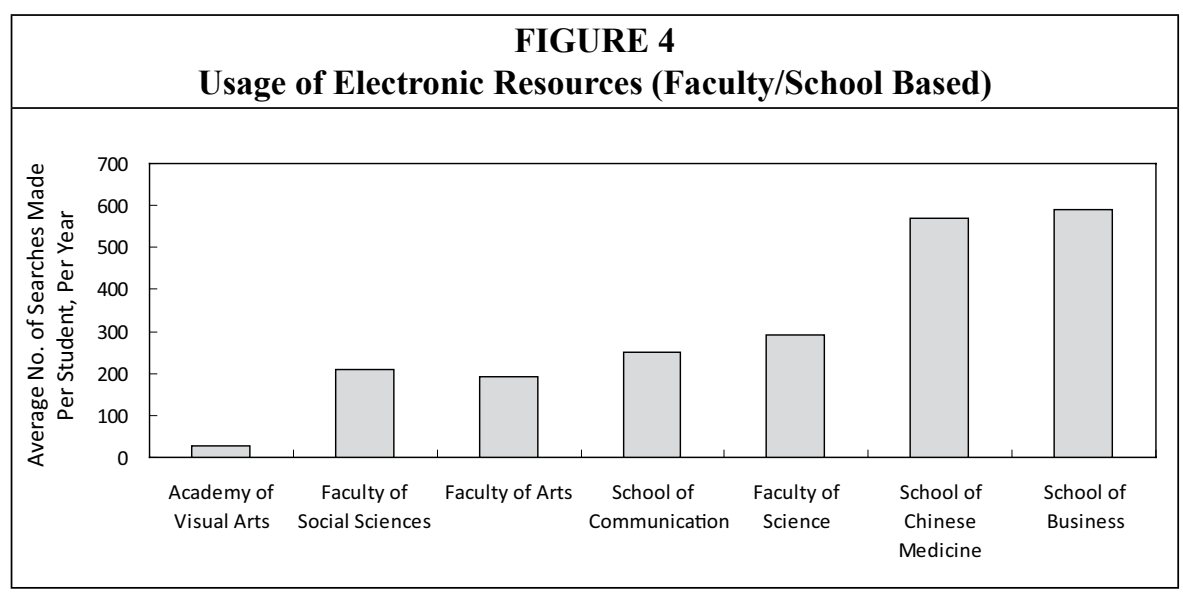




\section{Conclusion}

This is a highly experimental project for the HKBU Library and the academic library sector as a whole. We were very glad to be able to establish a positive correlation between book and multimedia loans and students' academic performance for most Faculties/Schools, by using 8,701 sets of data. We believe we have demonstrated our value on student learning outcomes. Nevertheless, books and audiovisual materials are just two of the three major types of resources libraries are providing today. To generate a more comprehensive picture, we would like to see us or other libraries to be able to establish a mathematical relationship between student usage of electronic resources and their GPAs in the near future.

\section{Notes}

1. American Library Association, The Library Survey Questionnaire (Chicago, American Library Association, 1924).

2. Library Association, A Century of Public Library Service: Where Do We Stand To-day? Centenary Assessment (London: Library Association, 1950).

3. Charles B. Weinberg, "The University Library: Analysis and Proposals," Management Science 21, no. 2 (1974): 130-40.

4. Denise Troll Covey, Usage and Usability Assessment: Library Practices and Concerns (Jan. 2002). Available online at www.diglib.org/pubs/dlf096/. [Accessed 9 April 2010].

5. Steve Hiller, Martha Kyrillidou, and Jim Self, "When the Evidence Is Not Enough: Organizational Factors That Influence Effective and Successful Library Assessment," Performance Measurement and Metrics 9, no. 3 (2008): 223-30.

6. William H. Walters, "Expertise and Evidence in the Assessment of Library Service Quality," Performance Measurement and Metrics 4, no. 3 (2003): 98-102.

7. W. Patrick Leonard, "On My Mind: This Year Is Different: Facing Outcome Assessment," The Journal of Academic Librarianship 18, no. 4 (1992), 228, 231.

8. Ronald R. Powell, "Impact Assessment of University Libraries: A Consideration of Issues and Research Methodologies," Library \& Information Science Research 14, no. 3 (1992), 245-57.

9. Ibid. 1966).

10. Patricia B. Knapp, The Monteith College Library Experiment (New York: Scarecrow Press,

11. Andrew M. Robinson and Karen Schlegl, "Student Bibliographies Improve When Professors Provide Enforceable Guidelines for Citations," Portal-Libraries and the Academy 4, no. 2 (2004): 275-90.

12. P. Barkey, "Patterns of Student Use of a College Library," College \& Research Libraries 20, no. 2 (1965), 115-18.

13. K. De Jager, "Library Use and Academic Achievement," South African Journal of Library $\mathcal{E}$ Information Science 65, no. 1 (1997), 26-30.

14. I. Rowlands and D. Nicholas, "Understanding Information Behavior: How Do Students and Faculty Find Books?" The Journal of Academic Librarianship 34, no. 1 (2008), 3-15. doi:10.1016/j. acalib.2007.11.005.

15. G.W. Corder and D.I. Foreman, Nonparametric Statistics for Non-Statisticians: A Step-by-Step Approach (Hoboken, N.J.: John Wiley \& Sons, 2009).

16. J. Cohen, Applied Multiple Regression/Correlation Analysis for the Behavioral Sciences (Hillsdale, N.J.: L. Erlbaum Associates, 1983).

17. Ibid. 

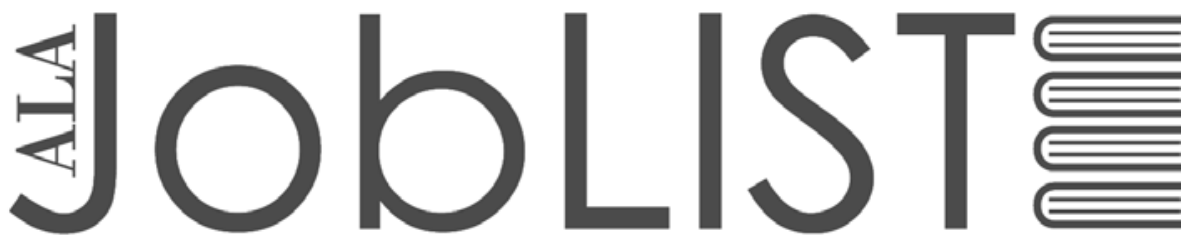

The \#1 source for jobs in Library and Information Science and Technology

\section{WHERE JOB SEEKERS AND EMPLOYERS GET RESULTS}

\section{JOB SEEKERS \\ Search and sort \\ hundreds of job ads by position type, employer, location, and more \\ Post your résumé for employers \\ Save your search as an RSS feed to alert you when new jobs matching your requirements are posted}

\section{EMPLOYERS}

Strengthen your candidate pool-ALA reaches the most engaged professionals and students

Simplify recruitmentone-stop advertising for online and print

Review posted résumés Connect with candidates

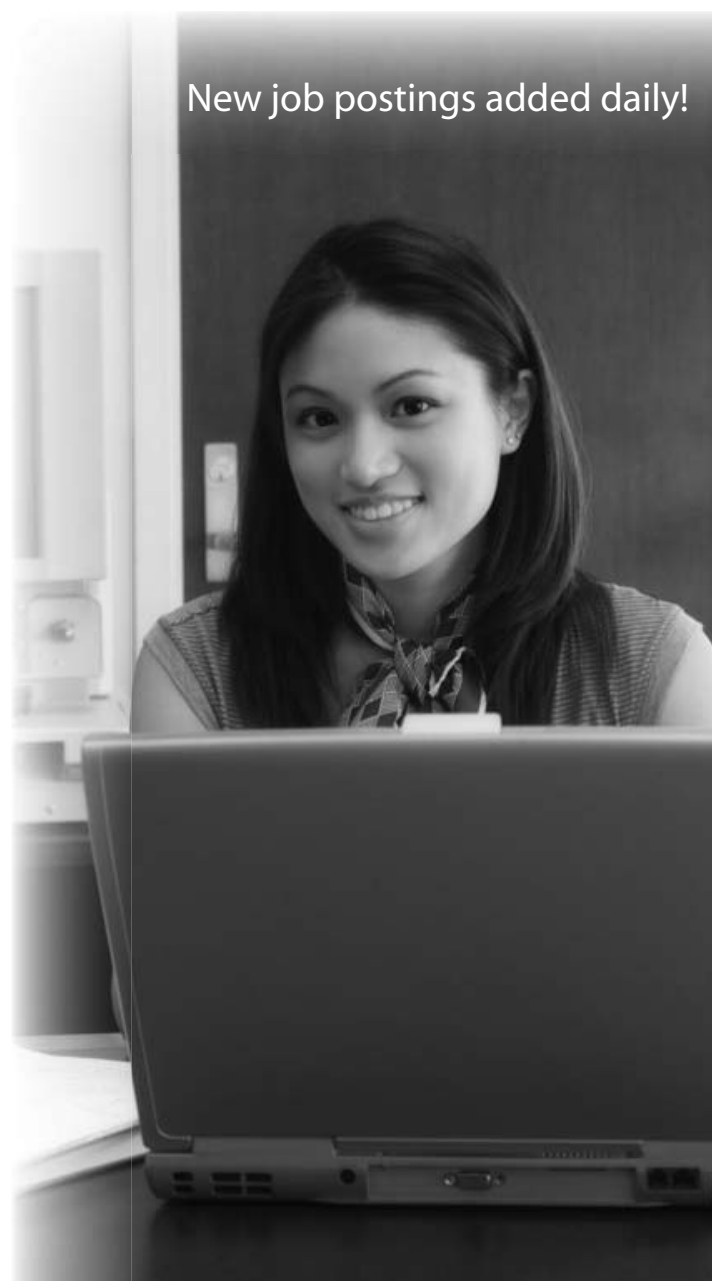

\section{ALA liberaries HRDR شeñ ACRL}

\section{joblist.ala.org}

